\title{
A MODIFICATION OF BOWMAN'S LACRYMAL PROBE
}

BY

\section{E. J. SOMERSET}

THE usual type of Bowman's lacrymal probe suffers from two disadvantages :-

(1) It is a double ended instrument which is usually used without gloves so that one end risks contamination from the hand.

(2) It is difficult to see the small numbers marked on the shaft and to know to which end they refer.

I have therefore had made a probe which is similar in general appearance to a very small urethral bougie. The numbers from

$00,0,1,2$, etc., are marked on the plate at the top end and are easily seen. The lower end is similar to the Bowman probe and the numbers correspond.

The probes have been made for me by Messrs. John Weiss and Son of 28\%, Oxford Street, W.1 and have been used during the last few months and have proved satisfactory in every way.

\section{ABSTRACTS}

\section{I.-UVEAL TRACT}

(1) Pavia, J. L. and Yrigoyen, L. (Buenos Aires).-Tuberculous macro-nodular iridocyclitis, spreading to the other parts of the eye. (Tuberculosis macro-nodular irido-ciliar con diseminacion al resto del ojo). Rev. Oto.-Neuro.-Oftal., Vol. XI, p. 185, July, 1936.

(1) Pavia and Yrigoyen describe a case of a child, aged eleven years, whose brother had pulmonary tuberculosis, and who was examined at a clinic to see if he had any early signs of the 
condition. Signs were found in the lungs and a positive skin test was obtained.

Later, the child developed a pleural effusion on two occasions; following the second effusion he developed an irido-cyclitis, and was admitted to hospital. The condition was very severe and the eye had to be excised.

On examination the cornea was found to be infiltrated with lymphocytes. The inflammatory process was so intense, that at the angle no definite structures could be made out on account of the infiltration of lymphocytes and the interstitial proliferation.

Tuberculous nodules were invading the ciliary processes; some of them caseating; the anterior and posterior chambers were filled with tuberculous tissue, and no normal vitreous could be found.

E. E. CASS.

(2) Malbran, J. and Androgue, E. (Buenos Aires).-Doyne's choroiditis. (Coroiditis de Doyne). Arch. de Oftal. de Buenos Aires, Vol. Xl, p. 529, 1936.

(2) Malbran and Androgue describe a case of this rare disease, which was first described by Doyne in 1899. Doyne discovered five out of a family of eight who were affected by this condition, which consists of small white spots in the papillo-macular region, some of them containing pigment.

The findings of other authors at later dates are given in detail. Treacher-Collins, in 1913, described the histological examination of a case. Alterations were found in the outer layers of the retina, similar to those changes occurring in "Drusenbilder." Hyaline deposits were found in the choroid, with nodules situated between the lamina vitrea and the retina. Lloyd, in 1936, included this condition among the heriditary macular degenerations, and noted that although the patients had good vision during youth, they had progressive failure of vision in later life.

The female sex is the most often affected, and the condition first appears about the age of puberty. The white patches in Doyne's choroiditis are larger than those found in Tay's and there is always pigment present. The differential diagnosis from retinitis albescens is that there are never any scotomata.

The authors have studied three families of Stargardt's degeneration, and say that whereas it affects both sexes, Doyne's choroiditis always affects the female sex. The case that they describe was that of a woman aged 20 years, who, however, had no family history of this condition.

E. E. CASS. 


\section{II.-RETINA}

(1) Allen, T. (Chicago).-Failures and successes in the operative treatment of detachment of the retina. Amer. Jl. of Ophthal., Vol. XIX, p. 1,000, 1936.

(1) Allen is impressed by the importance of a thorough general medical examination of a patient suffering from retinal detachment before undertaking operation, in particular, attention being paid to the cardio-vascular system and the possibility of post-operative haemorrhage.

In some cases he advocates a preliminary withdrawal of subretinal fluid in order to map out the precise site of retinal holes and to search for others that may have been hidden by folds of the detached area.

He comments on the difficulty of assessing the effect of electrolysis on the choroid and states that he prefers to use the Gradle electrode with the Walker diathermy outfit.

As regards drainage of sub-retinal fluid, an essential factor in retinal detachment surgery, the author feels that a $2 \mathrm{~mm}$. trephine hole remains patent and affords effective drainage longer than a number of minute punctures, 60 of which may close up in as short a time as one. He thinks that early post-operative examination is bad and prefers to wait five or seven days before doing the first dressing.

H. B. Stallard.

(2) Spinelli (Bologna).-Diathermy coagulation in detachment of the retina. (Sulla terapia del distacco di retina con la diatermo-coagulazione). Boll. d'Ocul., October, 1936.

(2) The chief interest of this paper is the method of localisation adopted by Spinelli; he has attached to the Gullstrand ophthalmoscope, a perimeter arc which carries a moveable wire, which, illuminated, throws on the cornea an image of a point surrounded by a ring; the ring should coincide with the limbus and the point mark the centre of the cornea. By a system of mirrors the observer is able to explore the fundus and at the same time see that the circle is imposed on the limbus. In a sliding tube is a plane glass engraved with a cross marked in millimetres. By sliding, this cross can be made to form an image on the fundus. The observer reads the apparent size of the disc in millimetres and then the distance between the hole and the extreme visible periphery. Then, moving the eye until the centre of the cross coincides with the hole, he turns the arc of the perimeter and moves the wire until the luminous circle is imposed on the limbus, this gives the meridian in which the hole lies. 
Knowing this and the distance of the hole from the limbus it is easy to plan the site of the operation.

HaROLD GRIMSDALE.

(3) Rinaldi and Arslan (Fadua). - Retinal exudate following sphenoidal sinus hyperostosis. (Retinite essudativa consecutiva a sinusite sfenoidale iperostosica). Boll. d'Ocul., October, 1936.

(3) Though inflammation of the nasal sinuses is recognised as a cause of retrobulbar neuritis, it is rare for the retina to be attacked. In the case related by Rinaldi and Arslan there was a large area of the retina extending from the nasal side below the disc to beyond the macula which was the seat of exudation, and was slightly raised. Vision was 6/12. The exudate hid the vessels, which beyond it, were engorged and tortuous. The nasal sinuses were cleared out and this was followed by speedy disappearance of the exudate and a return of vision to normal. The visual field, however, remained with loss of the superior half and the lower retinal arteries were converted into white cords: The authors think that the lesion was certainly not a simple blocking of the lower arteries but that the exudation was a separate process which may have occasioned the vascular changes.

Harold Grimsdale.

(4) Androgue, E. and Malbran, J. (Buenos Aires).-Exudative retinitis and retinal cysts. (Retinitis Exudativa y Quistis de la Retina). Arch. de Oftal. de Buenos Aires, March, 1936.

(4) Androgue and Malbran describe the diseases of Coats, Leber and von Hippel, and they consider there is a distinct difference between angiomatosis of the retina and retinitis exudativa externa; the latter disease is often limited to certain sectors of the fundus.

The condition is described in detail with its variations and the theories of its pathology, which have been observed by numerous recorders of cases.

The cause of retinitis exudativa externa has been thought to be due to tuberculosis, and that its toxins act either directly on the retina and the pigment epithelium, or indirectly, the numerous small vascular lesions produce alterations in the metabolism of the retina, such as occur in albuminuric retinitis. Some authors consider that the condition is due to syphilis.

The authors consider that vascular alterations are secondary, and when there is a primary vascular lesion, it is a true angiomatosis of the retina. 
Cysts of the retina may be accompanied by pigmentary changes which are more or less characteristic of foci of perivasculitis, they occur most frequently in young people, and the authors report several cases of this condition.

Fuchs has divided retinal cysts into five groups, the first group concerns those secondary to detachment, these occur between the pigment epithelium and the rest of the retina. The second group is produced by traction, and cysts are formed on the inner part of the retina. The third group is formed by the shrinking of the retina. The fourth group occurs in secondary glaucoma without retinal detachment. The fifth group consists of cysts occurring in tumour of the choroid.

The authors describe two more groups of cysts, the first is the cystic degeneration secondary to primary tumours of the retina and the second, congenital cysts occurring in microphthalmic eyes with colobomata.

E. E. Cass.

\section{III.-CONJUNCTIVA}

(1) Samuelson, A. (Stockholm).-Primary tuberculosis of the conjunctiva. Arch. of Ophthal., June, 1936.

(1) In his introductory remarks, Samuelson points out the rarity of this disease, its frequency at the Seraphimer Clinic being 1 in 60,000 cases if only primary ones are included, i.e., those due to ectogenous infection. In a few instances, the disease has been localised to the bulbar conjunctiva but in the majority (70-80 per cent.) it is the palpebral conjunctiva which is affected. In all cases, there was swelling of the pre-auricular lymph gland and in several the cervical lymph nodes were also affected. Pre-auricular lymphadenitis is often the first symptom noted by the patient. On examination of the conjunctiva, ulcers, granulations and proliferative lesions are found. The Mantoux reaction is usually positive but if it can be performed before the body has had time to develop allergy, it is negative, as occurred in the case of a boy aged 16 years reported by Vancea. The disease is more commonly caused by the bovine than by the human bacillus, probably because tuberculous cattle are not usually treated as a source of infection. Diagnosis has to be made from other causes of the Parinaud syndrome (e.g., primary syphilis of the conjunctiva, tularaemia, leptotrichosis and sporotrichosis of the conjunctiva) by histological examination and injection into guinea pigs of excised portions of the conjunctiva or preferably of the pre-auricular lymph gland. 
So far as treatment is concerned the best results are obtained by Finsen light. The author gives the details of three cases in which this method was entirely successful.

F. A. W-N.

(2) Aliquo-Mazzei (Siena).- Tubercle of the conjunctiva. (Sulla tubercolosi della congiuntiva). Boll. 'd'Ocul., August, 1936.

(2) Mazzei records two cases of tubercle of the conjunctiva, both of which were confirmed by inoculation of rabbits' eyes. Both cases were young boys ; in the first, the diagnosis was helped by the evidence of tubercle elsewhere; the local lesion was a large ulcer on the upper tarsal surface surrounded by small papillary granulations ; in the second case, the appearances of the upper lid suggested trachoma, but the presence of a dirty ulcer on the lower tarsus, and swelling of the pre-auricular gland suggested tubercle or Parinaud's conjunctivitis; the biological test showed tubercle. In this boy there were no other signs of tubercle and the author concludes that the disease was primary in the conjunctiva. $\mathrm{He}$ discusses the possibility of this, and decides that there must be some small lesion of the epithelium to allow the entrance of the bacilli; and that infection cannot take place through uninjured conjunctiva.

\section{Harold Grimsdale.}

(3) Gardilcic, Ante (Zagreb). - On experiments with a new treatment of trachoma and its results. (Ueber Versuche mit einer neuartigen Trachombehandlung und deren Ergebnisse). Arch. f. Ophthal., Vol. CXXXV, p. 293.

(3) Gardilcic's experiments on the treatment of trachoma, which extended over a number of years, were at first directed to the use of alkaline substances to combat a local acidosis; the results with these alone, however, were mostly negative, although the principle underlying this form of attack was considered useful in combination with the action of other drugs.

$\mathrm{He}$ then turned his attention to oxidising agents, substances giving off free chlorine. Various hypochlorites were employed, both as drops and with massage, and it was found that salts of heavy metals, liberating active chlorine (of which a silver compound was best) were more effective than the hypochlorites of $\mathrm{Na}$ or $\mathrm{K}$.

The use of nascent chlorine as the active principle does not satisfy the author in his search for an ideal agent in the treatment of trachoma in its various forms and complications, but in spite of certain disadvantages it was found more effective, better tolerated, and possesses a more varied action on the symptoms of 
the disease than any of the other chemical agents usually employed. It has a beneficial effect on mixed infections and on scrofulous symptoms in trachoma and non-trachomatous cases.

As regards the conjunctiva, the swelling, redness and infiltration generally subsided after its use, as also the trachoma granules and the papillary hypertrophy.

Infiltrations of the cornea were absorbed by this mode of treatment more quickly than usually, and cases in which other drugs had been of no avail cleared up after its use. Corneal ulcers were checked and filled up with new tissue more quickly, and small maculae disappeared more or less completely.

Pannus too yielded to this treatment both in fresh cases and in advanced forms with subsequent improvement in vision (except in the cases with dense deep central opacities).

It was not possible to furnish exhaustive statistics as to the end-results, but while relapses due to various causes were observed the cures obtained in a large number of cases were lasting.

Thomas Snowball.

(4) Selinger, E. (Chicago).-Quinine therapy in trachoma. Chinese Med. Jl., October, 1930.

(4) Selinger states that he has been treating trachoma with quinine for some years and has been able to bring about a cure with less trouble than with any other drug. He says that quinine from its physiological properties is admirably suited for use in trachoma. It is bactericidal, and as an alkaloid can penetrate mucous membranes. It is a poison to leucocytes and lymphocytes and therefore hinder's their accumulation in the tissues. The method he employs is as follows. He uses a 10 per cent. solution quinine bisulphate; he arms a rod with wool and dipping it into the solution, rubs the everted lid with a firm rolling movement until the conjunctiva takes on a milky-bluish colour. A separate applicator is used for each lid so that four are needed for each treatment; the treatment should be applied twice or three times a week. In addition he gives the patient 2 per cent. ointment of quinine to be put in the lids night and morning. The application of the quinine is followed by slight burning which can usually be relieved by cold compresses.

Harold Grimsdale. 


\section{IV.-MISCELLANEOUS}

(1) Mutch, J. R. (Aberdeen).-The pupil after cervico-thoracic sympathetic ganglionectomy; photographic observations in man. Edin. Med. Jl., December, 1936.

(1) In a most interesting paper Mutch reports upon six patients in whom the sympathetic chain has been divided at known levels, based upon photography of the eyes. Five of these patients underwent a unilateral operation, and thereby the sound side served as a control. In one case, records were taken while operation was in progress, the others have been observed at intervals up to two years. In five cases the tissue removed consisted of the sympathetic chain from the second thoracic ganglion to the stellate ganglion inclusive. In the sixth case Telford's technique, in which the chain is divided below the stellate ganglion and again below the third thoracic ganglion and the intervening segment removed, was followed. "'This modification was introduced by Telford in the belief that the sympathetic fibres in the first thoracic white ramus communicans are destined for the structures in the head and neck, so that by leaving it and the stellate ganglion intact, adequate sympathetic denervation of the arm is accomplished while the ocular results of the more extensive operation do not follow; this desirable result followed the one more limited operation." A full description of the technique used for photography is given and the nine figures on two plates show the results admirably. The author's conclusions are as follows.

"In man the position of the eyeball is unaltered after cervicothoracic sympathetic -neurectomy." In other words the enophthalmos which has often been described is more apparent than real.

"Narrowing of the palpebral fissure after the operation is due to raising of the lower lid, as well as to dropping of the upper lid. After sympathetic denervation, the pupil still responds to variations in illumination."

The paper is one that will repay perusal in the original.

R. R. J.

(2) Maitland Ramsay, A. - The retinal circulation in cardiovascular disease. Edin. Med. Jl., November, 1936.

(2) Maitland Ramsay's paper forms the seventh of a series of "Clinical Recollections and Reflections" now being published in the Edinburgh Medical Journal. The first half is mainlv physiological in nature and the author states three postulates with regard to the retinal capillaries. 
(1) That their distension accompanied by increased permeability of their walls to colloidal substances is the earliest sign of disease.

(2) That this may be recognised by lack of translucency of the ophthalmoscopic picture of the fundus oculi.

(3) That what can be seen with the ophthalmoscope in the eye is an index of what is taking place, hidden from view, in other parts of the body.

The retinal arteries are next considered with regard to hypertension, arterio sclerosis, haemorrhage from the retinal blood vessels, and retinitis; the last named being discussed under the headings of arterio-sclerotic, albuminuric and diabetic retinitis. The whole forms a very useful summary especially for the needs of the general practitioner; and illustrates a text on which the author is never tired of preaching, and rightly so, that the eye is part of the body and that the ophthalmic surgeon cannot be shut off in a water-tight compartment from general medicine. And that the more ophthalmology and general medicine are coordinated the better it will be for everyone concerned.

R. R. J.

(3) Sai (Trieste).-Radiography of the cerebral vessels. (Angiografia cerebrale). Riv. Oto.-Neuro.-Oftal., January-February, March-April, May-June, 1936.

(3) In this long paper, which is very fully illustrated, Sai describes a method of photographing the cerebral vessels during life; though this subject has little direct bearing on ophthalmology, yet it has interest for ophthalmologists, since it enables the surgeon to see any disturbance in the course of the vessels in cases of cerebral tumour, and thus is of assistance in accurate diagnosis.

The method consists in injecting into the common or the internal carotid a substance, " thorotrast," which is opaque to X-rays and is innocuous. The radiogram must be taken immediately after the injection; five seconds later the thorotrast has passed out of the arteries into the veins and a second radiogram taken then, will show the venous circulation.

The operation, therefore, must be performed in the X-ray room with the plates in position before the artery is exposed and the injection made. The difficulty of securing asepsis in these conditions seems, from the author's account, to be the chief risk.

Harol.d Grimsdale. 
(4) Gerber, Alexander, and Lambert, Robert K. (New York).Blue appearance of the fundus caused by prolonged ingestion of methylthionine Chloride. Arch. of Ophthal., September, 1936.

(4) Methylene blue has been used since 1880 as an intestinal antiseptic and since that date for many other conditions, such as carbon monoxide poisoning, tuberculous cystitis, gonorrhoea and malaria. In spite of this, Gerber and Lambert have been unable to find any reference in the literature to the ophthalmoscopic appearances produced by this drug. They therefore feel justified in reporting three cases in each of which the fundi appeared greenish blue, as though seen through a blue filter. The patients themselves were unaware of their condition and showed no departure from the normal in vision or visual fields. After absorbtion methylene blue remains in the tissues in a colourless form and does not appear blue except in the presence of oxygen. In the postmortem examination of a patient who died from renal tuberculosis and had taken methylene blue for 18 months the bladder, prostate and rectum became blue almost immediately on exposure to the air. When the eye was opened it was seen that the vitreous was blue but sections showed no blueness in any cells of the retina or other coats of the eye. The authors cannot be sure that this was not due to the dye having been washed out during dehydration and fixation. They are of opinion, however, that the blue appearance of the fundus with the ophthalmoscope in the living subject is due to colouration of the vitreous rather than the retina. Why there should be enough oxygen in the vitreous to allow the blue colour to develop is problematical.

F. A. W-N.

\section{(5) Cohen, Henry, M.D. (Liverpool).-Optic atrophy as the pre-} senting sign in pernicious anaemia. Lancet, November 21 , 1936.

(5) Cohen's paper was read at the meeting of the Association of British Neurologists at Edinburgh, June 12, 1936. In it he describes in detail two cases in which optic atrophy in apparently perfectly fit male subjects was the first sign of pernicious anaemia. The first case, aged 55 years, complained of failing vision for a year. A most searching examination disclosed little to account for the pallor of the discs which was present and the slight general contraction of the fields of vision. A diagnosis of optic atrophy, cause undetermined, was made. Close on six months later the man returned and was found to have pernicious anaemia. Treatbrought about a notable improvement in vision.

The second case, aged 46 years, gave a history of pernicious anaemia in his family. The eye condition was very similar to that 
in case one. There was no clinical evidence of subacute combined degeneration or, at first sight, of pernicious anaemia, but with the first case in memory together with the family history the author established the diagnosis by blood count and gastric analysis. Treatment has led to a great improvement in vision.

In his discussion of these two cases the author lays stress upon the fact that nervous symptoms in pernicious anaemia arise from, (a) the anaemia itself with resulting defective nutrition of nerve elements; $(b)$ loss of function followed by degeneration of nerve elements, due either to a toxin present in pernicious anaemia or the absence of a specific substance essential to neural nutrition; $(c)$ areas of softening due to small haemorrhages or thromboses. Only those symptoms resulting from temporary loss of function and due chiefly to the first two of these factors are potentially curable, regeneration in the central nervous system being absent.

All of us in the past must have met with cases of optic atrophy for which we could find no cause. It is to be hoped that the author's work here abstracted will lead to a diminution in the number of such cases.

R. R. J.

(6) Wood, D. J. (Cape Town).-Avulsion of an eye. South African Med.Jl., September, 1936.

(6) The case reported by Wood must be of extraordinary rarity. A man was admitted to hospital as an emergency case with a history of assault and stabbing in the left eye with a penknife. The globe was found protruding from the orbit and lay well beyond the eyelids. It was attached below by a small amount of fascia, and what appeared to be the tendon of the inferior rectus muscle. This was divided and the eye was removed with about two inches of nerve attached. There was no evidence of shock, though the man felt sick and haemorrhage was trifling in amount. There were, in addition to the main injury, two incised wounds, one at the outer canthus and one in the middle of the upper lid. A probe passed deeply through this along the orbital roof, but not into the orbital cavity.

Next day the patient complained of headache and blurring of vision in the remaining eye. Vision was $6 / 6$, but the field was very much contracted. Two days later the field was found to be larger in size but some loss of field in the upper temporal quadrant was present on discharge from hospital. The patient's statement was that "as he was stabbed his assailant thrust his thumb into the orbit, forced his eye up and out, and then pushed it forwards with the knife."

On examination the eyeball was found unruptured; the recti muscles had their tendinous ends left attached, rather less than 
$1 \mathrm{~cm}$. of each. The inferior oblique showed only a stump of tendon, and the superior oblique, about one inch.

The optic nerve measured $4.7 \mathrm{~cm}$. in length. It possessed its dural sheath for nearly $2.7 \mathrm{~cm}$., beyond this it was bare for about $2 \mathrm{~cm}$., that is the length of the nerve in the optic canal and cranial cavity.

The author notes that, on account of the anatomical arrangement of the fibres of the chiasma, " avulsion of a nerve from its chiasmal end will therefore be liable to damage the lower nasal decussating fibres from the opposite eye, and an upper temporal hemianopia is just what should, and did occur. Whether the initial small fields were quite genuine is uncertain, but one can imagine a condition of oedema, or of haemorrhage into the chiasma which, on clearing, allowed the restoration of most of the field. The field is now full except in the upper outer segment, where some contraction is still present."

R. R. J.

(7) Triandaf, E. and Nitzulesar (Rumania).-Ocular manifestations in trichinosis. (Manifestations oculaires dans la trichinose). Arch. d'Ophtal., Vol. LIII, p. 47, 1936.

(7) Triandaf and Nitzulesar review the literature of the ocular complications of trichinosis among which they mention oedema of the lid; sanguineous suffusion of the conjunctiva; the presence of parasites in the extra-ocular muscles and pain on movement of the eyes; exophthalmos ; mydriasis; paralysis of accommodation ; retinal haemorrhages and dilatation of the retinal veins; parasites in the retina and lesions in the outer nuclear and molecular layers, particularly around the capillaries. They report a family of three, father, mother, and a daughter who after eating some pork infected by the parasite became ill. The mother's symptoms were more severe than those of the other two who were but slightly affected. Oedema and tremor of the lids, painful ocular movements, defective distance and near vision were among the ocular manifestations. Eosinophilia, $1 \tau$ to 18 per cent., was present in all three cases.

H. 13. Stallard.

(8) Weingott, L. (Varsoire).- Pathogenesis, aetiology and treatment of g! aucomatous iridocyclitis. Arch. d'Ophtal., Vol. LIII, p. 672, 1936.

(8) Weingott discusses at length the pathogenic factors which lead to inflammation of the iris and ciliary body and to a rise of intra-ocular pressure. He stresses the importance of a thorough search for the cause and a careful general medical examination to determine the state of the patients' tissues, in particular those upon which the infective agent is operating. He gives clinical examples 
of cases of glaucomatous iridocyclitis in which a gonococcal focus was tracked down in the prostate and joints and associated with this were certain vascular degenerative changes due to alcoholism and syphilis. In the treatment of such cases he points out the importance of treating not only the cause but any associated disease. His case reports show some remarkable successes with gonococcal vaccine and, indeed, he feels that many cases of glaucomatous iridocyclitis will respond satisfactorily to medical attention and will not require an operation.

H. B. Stallard.

(9) Lewis, G. E., Raines, R. and Stewart, D. Stenhouse (Hull).Uveo-parotitis. Lancet, Vol. CCXXXI, p. 1204, 1936.

(9) Lewis, Raines and Stenhouse review the literature of uveoparotitis and describe the clinical course of a case under their care the general medical features of which began with a mild phlebitis of the legs, a carbuncle on the lip, unresolved right lower lobar pneumonia, septicaemia, pyuria and later angio-neurotic oedema. The patient's father had died from tuberculosis. Parotitis preceded iritis and in spite of a normal intra-ocular pressure during the illness the optic disc of the affected eye became cupped on the temporal side with a nasal field loss. The patient recovered completely but later had an urticarial rash, some angioneurotic oedema and a fainting attack.

In discussing the aetiology the authors are disposed to regard the disease as a local manifestation possibly due to any one of a variety of allergens which operate selectively on specifically hypersensitised tissues. Whilst tuberculin may often be the responsibie allergen they do not feel justified in regarding all cases of uveoparotitis as tuberculous.

H. B. Stallard.

(10) A. May Vianna (Faro, Portugal). - Auto-ophthalmoscopy. (L'auto-examen du fond de l'oeil). Ann. d'Ocul., Vol. CLXXII, p. 936, 1935.

(10) When looking into a plane mirror at $20 \mathrm{~cm}$. distance with $\mathrm{a}+13 \mathrm{D}$. lens in front of one eye, the other eye using an electric ophthalmoscope can see only a part of the temporal fundus. The optic disc will not be visible as the angle between the visual axes of the right and the left eye is too small. In order to see the disc and its surroundings it is necessary to displace the image of the observed eye more laterally by putting a properly inclined plane mirror, or better, a prism between the eye and the lens. It is an advantage to make the observing eye 3 to $4 \mathrm{D}$. myopic. A mydriatic has not been used for these auto-examinations.

Humphrey NeAme. 